\title{
Case Report: Japanese Encephalitis Associated with Chorioretinitis after Short-Term Travel to Bali, Indonesia
}

\author{
Karen Van, ${ }^{1 \star}$ Tony M. Korman, ${ }^{1,2}$ Suellen Nicholson, ${ }^{3}$ Robyn Troutbeck, ${ }^{4}$ David M. Lister, ${ }^{1}$ and lan Woolley ${ }^{1,2}$ \\ ${ }^{1}$ Monash Infectious Diseases, Monash Health, Clayton, Australia; ${ }^{2}$ Centre for Inflammatory Diseases, School of Clinical Sciences, Monash \\ University, Clayton, Australia; ${ }^{3}$ Victorian Infectious Diseases Reference Laboratory, The Peter Doherty Institute for Infection and Immunity, \\ Melbourne, Australia; ${ }^{4}$ Department of Ophthalmology, Monash Health, Clayton, Australia
}

\begin{abstract}
Japanese encephalitis (JE) virus is a mosquito-borne flavivirus endemic throughout Asia. Incidence in nonendemic countries is rare, with an estimate of less than one case per one million travelers. Most human JE infections are asymptomatic or cause a mild, nonspecific febrile illness. Neurological involvement, if present, is usually severe and associated with high mortality or ongoing neurological sequelae in survivors. Ocular manifestations are rare with JE, but uveitis has been described to be associated with other flavivirus infections, including West Nile virus. We report the first probable case of JE chorioretinitis acquired by a 45-year-old Australian traveler to Bali. This case highlights the importance of a detailed ocular examination when there is clinical suspicion of JE.
\end{abstract}

\section{CASE}

A 45-year-old Australian male visited Bali, Indonesia, for 10 days during the wet season in January (staying at resort hotels in Seminyak and Canggu). His medical history included asthma and restless leg syndrome, treated with pramipexole, levodopa, and carbidopa. Before travel, he received diphtheria/ tetanus/pertussis (acellular) and typhoid vaccines and commenced doxycycline for malaria prophylaxis. Aside from a day trip to Ubud, holiday activities were primarily resort based, without any camping or other outdoor activities. Despite this, the patient recalled multiple mosquito bites. He had no previous travel to a Japanese encephalitis virus (JEV)-endemic area.

One day after returning to Australia, he developed fever, vomiting, and myalgia. On day 4 of symptom onset, he developed confusion and expressive dysphasia and was admitted to hospital. On examination, he was afebrile, disoriented, dysphasic, and had bilateral conjunctival injection with no rash noted. The patient underwent ophthalmological assessment. Visual acuity was $6 / 6$ in the right eye and $6 / 7.5$ in the left. Slit-lamp biomicroscopy showed fine keratic precipitates on the corneal endothelium and moderate anterior chamber inflammation. Examination of the posterior pole revealed bilateral vessel tortuosity and bilateral pale chorioretinal lesions (Figure 1 left eye). Peripheral intraretinal hemorrhages were also seen in both eyes.

Cerebrospinal fluid (CSF) microscopy on day 5 of symptoms revealed lymphocytes $243 \times 10^{6}$ cells/L and polymorphonuclear leukocytes $18 \times 10^{6} \mathrm{cells} / \mathrm{L}$. The CSF protein was $1.4 \mathrm{~g} /$ $\mathrm{L}$ (normal range, 0.1-0.3) and normal glucose $3.4 \mathrm{mmol} / \mathrm{L}$. Magnetic resonance imaging (MRI) showed signal changes in bilateral, asymmetrical mesial temporal lobe involving the cortex and some subcortical white matter, the right thalamus, and the left head of caudate nucleus (Figure 2). Intravenous acyclovir and ceftriaxone were commenced but ceased after blood and CSF bacterial cultures were negative, and CSF herpes simplex viruses 1 and 2, cytomegalovirus, and varicella zoster viruses were not detected using PCR tests. Cerebrospinal fluid cryptococcal antigen was negative. Chikungunya (and other

*Address correspondence to Karen Van, Monash Infectious Diseases, 246 Clayton Rd., Clayton 3168, Australia. E-mail: karen.van712@ gmail.com alphaviruses), hendra/nipah virus, leptospira, and toxoplasma were not detected using PCR on CSF.

Two weeks into admission, he developed right face and arm myoclonic jerks associated with delirium and psychotic features. Risperidone was trialed with no improvement. Electroencephalography showed diffuse slowing, suggestive of underlying diffuse encephalopathy. After 3 weeks in rehabilitation, the patient's delirium resolved; however, he had ongoing impairment in memory and concentration.

Serum JEV IgM was detected on day 4 of symptoms. Seroconversion was demonstrated for JEV (IgG not detected by immunofluorescence at day 4 of symptom onset; titer $>160$ on day 11 and $>1,280$ on day 30$)^{1}$ but not for potentially cross-reacting flaviruses including dengue virus, Murray Valley encephalitis virus (MVEV), West Nile virus (WNV), and Zika virus (Table 1).

Cerebrospinal fluid JEV IgG and PCR were negative at day 5. Flaviviruses were negative using PCR on CSF: dengue types 1, 2, and 3 virus, MVEV, WNV, Kunjin strain, and yellow fever virus.

\section{DISCUSSION}

Japanese encephalitis virus belongs to the family Flaviviridae and is transmitted between animals and human host by

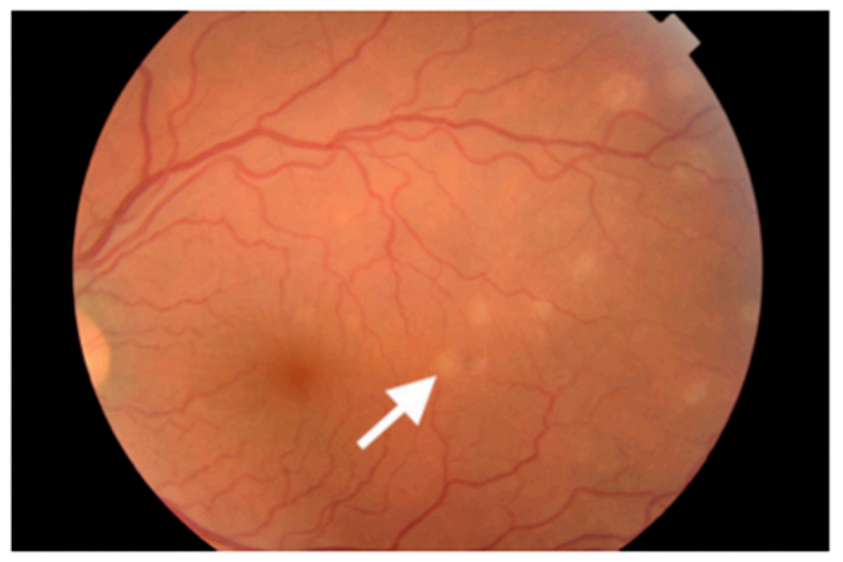

FIGURE 1. Left eye shows the chorioretinal lesions (see arrow). This figure appears in color at www.ajtmh.org. 


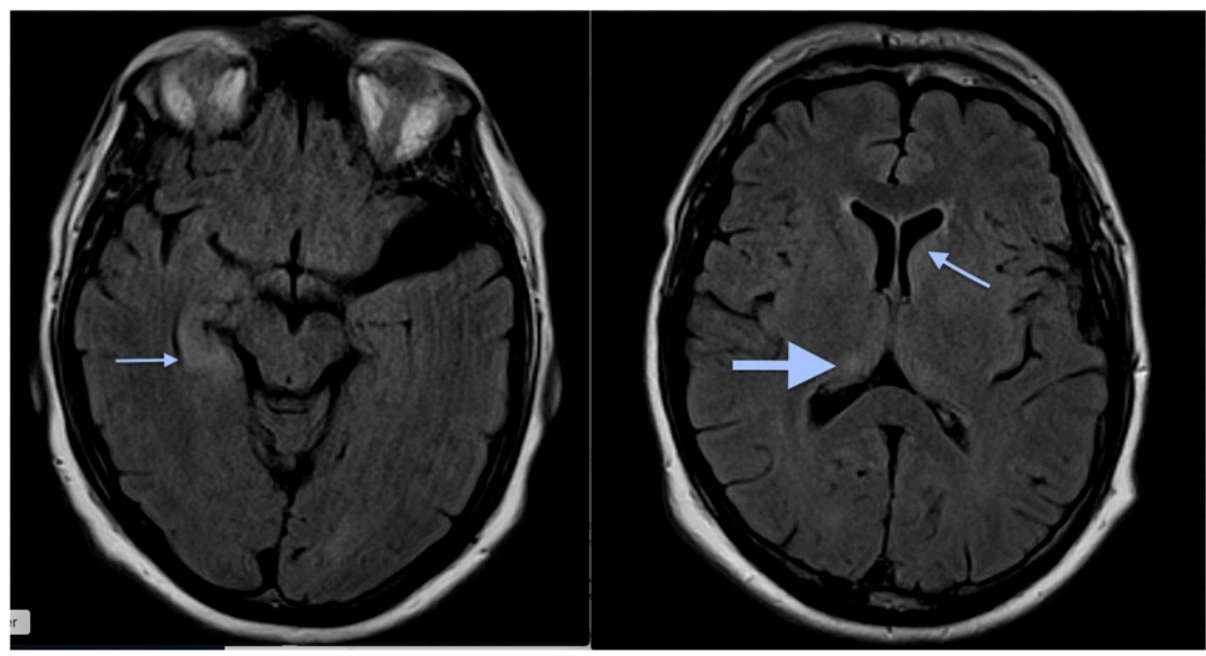

FIGURE 2. Magnetic resonance imaging scan demonstrating signal changes in the mesial temporal lobe involving the cortex and some subcortical white matter (see thin horizontal arrow), the right thalamus (see thick arrow), and the left head of caudate nucleus (see diagonal arrow). This figure appears in color at www.ajtmh.org.

Culex mosquitoes. In the tropics, JEV transmission occurs year-round, whereas seasonal epidemics begin during the rainy seasons when the mosquito density is maximum. ${ }^{2}$ Most JEV infections are asymptomatic or mild. The WHO estimates 68,000 clinical cases of JE globally each year. Approximately 1 in 250 infections of serologically confirmed JE develops severe symptoms. Neurologic disease typically develops in patients after an incubation period of 5-15 days (although this period can be as brief as 2-3 days) and a short, nonspecific febrile prodrome. ${ }^{3}$ About $30 \%$ of patients admitted to hospital with JE die, and around half of the survivors have severe neurological sequelae. ${ }^{4}$ In areas with better hospital facilities, there is a reduction in mortality but a concomitant increase in the number of patients with sequelae. ${ }^{4}$

Very few cases of JE have been described in Australian travelers since the first report in $1998 .{ }^{4}$ In this case, the presence of serum JEV-specific IgM antibody and IgG seroconversion with greater than 4-fold rise in titer of JEV-specific antibody at least 14 days apart (between days 11 and 30 of symptom onset) fulfills the WHO laboratory confirmation of a JEV infection. ${ }^{5} \mathrm{~A}$ false-positive result is unlikely without recent JE vaccination and absence of serological evidence of other potentially cross-reacting flaviviruses. Magnetic resonance imaging findings in bilateral thalami are characteristic of flavivirus encephalitides; however, other areas of involvement may also be seen. ${ }^{6,7}$

To our knowledge, this is the first description of chorioretinitis associated with JE and highlights the importance of a detailed ocular examination when there is clinical suspicion of JE. Viral and bacterial arthropod vector-borne infections, namely, WNV, Rift Valley fever phlebovirus, dengue virus, chikungunya virus, and rickettsia have been associated with

TABLE 1

Serology results

\begin{tabular}{|c|c|c|c|}
\hline & \multicolumn{3}{|c|}{ Days from symptom onset } \\
\hline & Day 5 & Day 11 & Day 30 \\
\hline \multicolumn{4}{|l|}{ Japanese encephalitis virus } \\
\hline $\lg G$ & $<10$ (negative) & > 160 (positive) & $>1,280$ (positive) \\
\hline $\lg M$ & Detected & Detected & Detected \\
\hline Bartonella IgG & - & $<128$ & - \\
\hline \multicolumn{4}{|l|}{ Chikungunya virus } \\
\hline $\lg G$ & $<10$ (negative) & - & $<10$ (negative) \\
\hline $\lg M$ & ND & - & ND \\
\hline \multicolumn{4}{|l|}{ Dengue virus } \\
\hline $\lg \mathrm{G}$ & ND & Low positive & - \\
\hline $\lg M$ & ND & ND & - \\
\hline NS1 antigen & ND & ND & - \\
\hline HIV antigen/antibody & ND & - & - \\
\hline West Nile virus total antibody & - & ND & - \\
\hline $\begin{array}{l}\text { Murray Valley encephalitis virus total } \\
\text { antibody }\end{array}$ & - & ND & - \\
\hline \multicolumn{4}{|l|}{ Zika } \\
\hline $\lg G$ & - & - & ND \\
\hline $\lg M$ & - & - & ND \\
\hline
\end{tabular}

IgG = immunoglobulin G; IgM = immunoglobulin M; NS1 = non structural protein 1; HIV = human immunodeficiency virus; ND = not detected. Testing was performed at the Victorian Infectious Diseases Reference Laboratory. ${ }^{13-15}$ 
ocular manifestations. The pathophysiology is almost always hematogenous spread of infection from another part of the body to the highly vascular uvea, with a breach in the bloodeye barrier. ${ }^{8}$ West Nile virus is closely related to JEV and is associated with common ocular manifestations including chorioretinitis, retinal hemorrhages, and vitritis. ${ }^{9}$ Typical bilateral or rarely unilateral multifocal chorioretinitis is the most common ocular manifestation of WNV associated in almost $80 \%$ of patients with acute WNV-associated neurological illness. ${ }^{10}$ Most patients have no ocular symptoms or present with mildly reduced vision or floaters.

For most travelers who travel to Asia, the risk of JE is very low but varies based on destination, length of travel, season, and activities. ${ }^{2}$ Japanese encephalitis vaccine is recommended for travelers who plan to spend 1 month or more in endemic areas during JEV transmission season. It should also be considered for shorter term travelers traveling during the wet season, if there is considerable outdoor activity or the accommodation is not mosquito-proof. ${ }^{11}$

Indonesia is a popular tourist destination for Australians and others, in particular Bali, where JEV is endemic. Although JE is uncommon in returned travelers, ${ }^{12}$ its high mortality rate and serious permanent neurologic sequelae should prompt consideration for JE immunization. With newer, safer, single-dose vaccines, JEV prevention and vaccination should be part of pretravel counseling.

Received April 28, 2019. Accepted for publication June 17, 2020.

Published online August 10, 2020.

Acknowledgment: We would like to thank Linda Santamaria for feedback received.

Authors' addresses: Karen Van, Monash Infectious Diseases, Monash Health, Clayton, Australia, E-mail: karen.van712@gmail.com. Tony M. Korman and lan Woolley, Department of Infectious Diseases, Monash Health, Melbourne, Australia and Centre for Inflammatory Diseases, School of Clinical Sciences, Monash University, Clayton, Australia, E-mails: tony.korman@monash.edu and ian.woolley@monash.edu. Suellen Nicholson, Victorian Infectious Diseases Reference Laboratory, The Peter Doherty Institute for Infection and Immunity, Melbourne, Australia, E-mail: suellen.nicholson@vidrl.org.au. Robyn Troutbeck, Department of Ophthalmology, Monash Health, Melbourne, Australia, E-mail: rtroutbeck@gmail.com. David M. Lister, Alice Springs Hospital, Alice Springs, Australia, E-mail: david.michael.lister@ gmail.com.

\section{REFERENCES}

1. Williams SA et al., 2013. Low seroprevalence of Murray Valley encephalitis and Kunjin viruses in an opportunistic serosurvey, Victoria 2011. Aust N Z J Public Health 37: 427-433.

2. Misra UK, Kalita J, 2010. Overview: Japanese encephalitis. Prog Neurobiol 91: 108-120.

3. Solomon T, 2004. Flavivirus encephalitis. N Engl J Med 351: 370-378.

4. Solomon T, Dung NM, Kneen R, Gainsborough M, Vaughn DW, Khanh VT, 2000. Japanese encephalitis. J Neurol Neurosurg Psychiatr 68: 405-415.

5. World Health Organization, 2019. Vaccine Preventable Diseases Surveillance Standards: Japanese Encephalitis. Geneva, Switzerland: WHO. Available at: https://www.who.int/immunization/monitoring surveillance/burden/vpd/WHO_SurveillanceVaccinePreventable_ 10_JapaneseEncephalitis_BW_R1.pdf?ua $=1$.

6. Misra UK, Kalita J, Phadke RV, Wadwekar V, Boruah DK, Srivastava A, Maurya PK, Bhattacharyya A, 2010. Usefulness of various MRI sequences in the diagnosis of viral encephalitis. Acta Trop 116: 206-211.

7. Einsiedel L, Kat E, Ravindran J, Slavotinek J, Gordon DL, 2003. MR findings in Murray Valley encephalitis. AJNR Am J Neuroradiol 24: 1379-1382.

8. Lee JH, Agarwal A, Mahendradas P, Lee CS, Gupta V, Pavesio CE, Agrawal R, 2017. Viral posterior uveitis. Surv Ophthalmol 62: 404-445.

9. Hills S, Fischer M, Solomon T, 2019. Japanese Encephalitis. Waltham, MA: UpToDate Inc. Available at: https://www.uptodate. com. Cited March 11, 2019.

10. Khairallah M, Kahloun R, Ben Yahia S, Jelliti B, Messaoud R, 2013. New infectious etiologies for posterior uveitis. Ophthalmic Res 49: 66-72.

11. Australian Government Department of Health, 2002. The Australian Immunisation Handbook. Canberra, ACT: Commonwealth of Australia. Available at: https://immunisationhandbook.health.gov.au/ vaccine-preventable-diseases/japanese-encephalitis. Updated June 1, 2018; Cited March 11, 2019.

12. Ratnam I et al., 2013. Low risk of Japanese encephalitis in shortterm Australian travelers to Asia. J Travel Med 20: 206-208.

13. Huang GKL, Tio SY, Caly L, Nicholson S, Thevarajan I, Papadakis G, Catton M, Tong SYC, Druce J, 2017. Prolonged detection of Japanese encephalitis virus in urine and whole blood in a returned short-term traveler. Open Forum Infect Dis 4: ofx203.

14. Russell JS et al., 2018. The first isolation and whole genome sequencing of Murray valley encephalitis virus from cerebrospinal fluid of a patient with encephalitis. Viruses 10: 319.

15. Wilson HL, Tran T, Druce J, Dupont-Rouzeyrol M, Catton M, 2017. Neutralization assay for Zika and dengue viruses by use of real-timePCR-based endpoint assessment. J Clin Microbiol 55: 3104-3112. 